\title{
High heat flow in the Trans-Hudson Orogen, central Canadian Shield
}

\author{
L. Guillou-Frottier ${ }^{1}$, C. Jaupart ${ }^{2}$, J.C. Mareschal ${ }^{1}$, C. Gariépy ${ }^{1}$, G. Bienfait ${ }^{2}$, \\ L.Z. Cheng ${ }^{1}$ and R. Lapointe ${ }^{1}$
}

\begin{abstract}
Nine new heat flow and heat production measurements are presented for the Trans-Hudson Orogen, an Early Proterozoic Province between the Archean Superior and Hearne Provinces of the Canadian Shield. Seventeen heat flow values now available in this region range between 23 and $81 \mathrm{~mW} \cdot \mathrm{m}^{-2}$. The highest value is anomalous and is due to heat refraction effects in and around highly conducting quartzite formations. When refraction effects are accounted for, the Flin Flon and Thompson belts appear as distinct crustal blocks with different mean heat flow values of $42 \pm 3\left(s . d\right.$.) $m W . m^{-2}$ and $54 \pm 8(s . d) m. W . m^{-2}$. Such differences can be accounted for by variations in the amount of felsic rocks in the uppermost $15 \mathrm{~km}$ of the crust. Comparison between heat flow and elastic thickness studies show that variations in elastic thickness of the lithosphere are not thermally induced.
\end{abstract}

\section{Introduction}

The Trans-Hudson Orogen (THO), located between the Archean Hearne and Superior cratons, represents a tectonic collage of several microcontinents and arc terranes which amalgamated in the Early Proterozoic, between 1.8-1.9 Ga [Lewry and Collerson, 1990]. Juvenile volcanic arcs are preserved within juxtaposed belts, whereas reworked Archean gneisses are exposed in the Thompson belt, at the THO-Superior boundary [e.g. Bleeker, 1990]. Crustal thickness varies between 38 and $48 \mathrm{~km}$ [e.g. Lucas et al., 1999]. The THO is located in the central part of the North American craton where the elastic thickness of the lithosphere is largest [Pilkington, 1991].

So far, only eight heat flow measurements were available from sites sparsely distributed across the THO [Drury, 1985; and references therein]. The objective of this paper is to present new data and discuss their implications for crustal structure and composition, and for the thermal regime of the Canadian Shield.

\section{Heat flow data}

Heat flow and heat production data are presented for nine new sites in the THO (Table 1 and Figure 1). The

\footnotetext{
${ }_{2}^{1}$ GEOTOP, Université du Québec à Montréal, Canada

2 Institut de Physique du Globe de Paris, France
}

Copyright 1996 by the American Geophysical Union.

Paper number 96GL02895.

0094-8534/96/96GL-02895\$05.00 heat flow $Q$ is determined from the measurements of the temperature gradient in boreholes and of the conductivity of rock samples :

$$
Q=k \frac{\partial T}{\partial z}
$$

where $k$ is the thermal conductivity, $T$ is temperature and $z$ is depth. The measurements procedures are described in Mareschal et al. [1989] and Pinet et al. [1991]. Analytical errors on heat production measurements are negligible and the only source of uncertainty is the sampling. Comparison of mean heat production from neighboring boreholes provides an estimate of this uncertainty, which is small for this study. Stable temperature gradients were obtained over several hundreds of meters (Table 1 and Figure 2). A climatic correction for the effect of Pleistocene glaciations was applied to the data following Jessop [1971]. This was done for consistency with previously published values although such corrections may be overestimated as suggested by Sass et al. [1971]. In all but one site, the climatic correction is less than $10 \%$ of the measured value.

Figure 1 shows the presently available heat flow data in the eastern THO. The two extreme heat flow values in the THO (23 and $81 \mathrm{~mW} \cdot \mathrm{m}^{-2}$ ) are also the lowest and highest values yet recorded in the Canadian Shield. The very low value at Lynn Lake [Drury, 1985] is not explained and will need further investigation.

\section{Heat flow variations}

Heat flow values are consistently lower in the Flin Flon belt (FFB) than in the Thompson belt (TB). In the FFB, heat flow varies within a restricted range of 38 to $46 \mathrm{~mW} \cdot \mathrm{m}^{-2}$. In contrast, it is highly variable in the $\mathrm{TB}$, with values ranging from 45 to $81 \mathrm{~mW} \cdot \mathrm{m}^{-2}$. These distinct thermal signatures are related to differences in surface geology. The FFB is interpreted as a collage of island arcs and oceanic plateaux with mafic lavas and calc-alkaline plutons dominating the surface lithology. In the TB, the rock types are more contrasted and vary over a scale of a few kilometers. They include metasediments, mafic to ultramafic lavas, granodiorites, and reworked Archean gneisses. Large variations in heat production and thermal conductivity are observed in the TB (Table 1).

The high heat flow values near Thompson were obtained in highly conductive quartz-rich metasedimentary formations. In this area, almost vertical slices of sedimentary rocks, about $300 \mathrm{~m}$ wide and $1,000 \mathrm{~m}$ deep, are sandwiched between high-grade gneisses due to a 
Table 1. Heat Flow and Heat Production Data

\begin{tabular}{|c|c|c|c|c|c|c|c|c|c|c|c|c|c|c|}
\hline $\begin{array}{l}\text { Site } \\
\text { Hole number }\end{array}$ & $\begin{array}{c}\text { Lat } \\
\text { (north) }\end{array}$ & $\begin{array}{c}\text { Lon } \\
\text { (west) }\end{array}$ & $\begin{array}{l}\text { Alt } \\
(m)\end{array}$ & $\begin{array}{c}\text { Dip } \\
(\text { deg })\end{array}$ & $\begin{array}{l}\Delta h \\
(m)\end{array}$ & $N_{k}$ & $\begin{array}{c}\langle k\rangle \\
*\end{array}$ & $N_{A}$ & $\begin{array}{c}\langle A\rangle \\
\ddagger\end{array}$ & $\begin{array}{c}G \\
K / k m \\
\end{array}$ & $\begin{array}{l}9 \\
0\end{array}$ & $\begin{array}{c}\sigma_{Q} \\
@\end{array}$ & $\begin{array}{c}\Delta Q \\
@\end{array}$ & $\begin{array}{l}Q c \\
0\end{array}$ \\
\hline Wabowden & & & & & & & & & 06 & & & & & 45 \\
\hline 93-01 & 545254 & 983838 & 229 & 76 & $390-800$ & 13 & 2.73 & 11 & 0.68 & 14.6 & 39.9 & 16 & 27 & 43 \\
\hline $93-02$ & 545254 & 983838 & 229 & 71 & 280.530 & 8 & 2.92 & 2 & 0.47 & 147 & 42.8 & 31 & 34 & 46 \\
\hline Flin-Flon 3 & & & & & & & & & 0.3 & & & & & 42 \\
\hline $93-03$ & 544700 & 1015300 & 335 & 88 & $380-480$ & 7 & 3.17 & 7 & 0.20 & 12.1 & 38.5 & 2.5 & 2.9 & 41 \\
\hline $93-04$ & 544714 & 1015310 & 335 & 88 & $450-520$ & 9 & 2.95 & 8 & 0.35 & 12.2 & 35.9 & 1.7 & 3.0 & 39 \\
\hline 93.07 & 544714 & 1015318 & 320 & 88 & $210-540$ & 3 & 3.20 & 3 & 0.18 & 131 & 41.8 & 2.6 & 2.8 & 45 \\
\hline Schist Lake & & & & & & & & & 0.3 & & & & & 39 \\
\hline $\begin{array}{l}93-05 \\
\text { Reed Lake }\end{array}$ & 544311 & 1014937 & 304 & 65 & $640-780$ & 13 & 3.57 & 11 & 0.3 & 9.3 & 33.2 & 2.5 & 5.8 & $\begin{array}{r}39 \\
40\end{array}$ \\
\hline $93-06$ & $5434 \quad 17$ & 1002250 & 280 & 80 & $160-420$ & 9 & 2.74 & 6 & $\begin{array}{l}0.3 \\
0.35\end{array}$ & 137 & 37.4 & 2.5 & 22 & $\begin{array}{l}40 \\
40\end{array}$ \\
\hline Birchtree mine 1 & & & & & & & & & 0.7 & & & & & 50 \\
\hline $\begin{array}{l}94-05 \\
94-03\end{array}$ & $\begin{array}{llll}55 & 41 & 59 \\
55 & 42 & 10\end{array}$ & $\begin{array}{l}975350 \\
975410\end{array}$ & $\begin{array}{l}221 \\
207\end{array}$ & $\begin{array}{l}72 \\
75\end{array}$ & $\begin{array}{c}160-440 \\
80-170\end{array}$ & $\begin{array}{l}7 \\
0\end{array}$ & 3.27 & $\begin{array}{l}5 \\
0\end{array}$ & 0.75 & 14.7 & 48.0 & 1.6 & 2.0 & 50 \\
\hline Birchtree mine 2 & 354210 & 910210 & & & ou-1.0 & & & & $1.6^{-}$ & 14.8 & - & - & - & $64^{-}$ \\
\hline $\begin{array}{l}\text { 94-06 } \\
\text { Thompson station }\end{array}$ & 554215 & 975158 & 229 & 80 & $200-630$ & 10 & 3.72 & 11 & 1.36 & 16.9 & 62.7 & 3.9 & 1.7 & 81 \\
\hline 94-07 & 554425 & 974922 & 206 & 86 & $420-950$ & 12 & 517 & 12 & 1.45 & 14.8 & 76.4 & 5.1 & 30 & 79 \\
\hline $\begin{array}{c}94-13 \\
\text { Moak Lake }\end{array}$ & 554446 & 974848 & 206 & 82 & $310-540$ & 5 & 5.35 & 6 & $\begin{array}{l}1.08 \\
1.6\end{array}$ & 14.9 & 79.6 & 30 & 3.5 & $\begin{array}{c}83 \\
53\end{array}$ \\
\hline $94-08$ & $\begin{array}{llll}55 & 54 & 21\end{array}$ & 974006 & 206 & 76 & $120-250$ & 6 & 3.21 & $\mathbf{5}$ & 1.69 & 16.7 & 53.4 & 1.6 & 1.3 & 55 \\
\hline 94-09 & 555353 & 974041 & 214 & 77 & $340-540$ & 8 & 3.43 & 7 & 1.61 & 14.2 & 48.8 & 2.1 & 2.0 & 51 \\
\hline Pipe mine & & & & & & & & & 1.0 & & & & & 49 \\
\hline 94-10 & $\begin{array}{lll}55 & 29 & 17\end{array}$ & $\begin{array}{lll}98 & 07 & 50\end{array}$ & 210 & 83 & $270-370$ & 4 & 292 & 5 & 1.38 & 15.6 & 455 & 1.0 & 16 & 47 \\
\hline $94-11$ & $\begin{array}{lll}55 & 29 & 10\end{array}$ & 980754 & 215 & 86 & $530-820$ & $\mathbf{9}$ & 321 & 10 & 0.78 & 155 & 49.6 & 5.3 & 16 & 51 \\
\hline 94-12 & $\begin{array}{lll}55 & 29 & 17\end{array}$ & 980750 & 210 & 81 & $440-870$ & 12 & 2.91 & 6 & 1.06 & 16.4 & 479 & 1.4 & 1.1 & 49 \\
\hline
\end{tabular}

New heat flow and heat production data measured in the Trans-Hudson Orogen. Parameters are $\Delta h$, depth range for heat flow determination: $N_{k}$ and $N_{A}$, number of samples for conductivity and heat production measurements; $\langle\boldsymbol{k}\rangle$ and $\langle A\rangle$, average thermal conductivity and heat production rate; $G$, thermal gradient; $Q$, heat flow; $\sigma_{Q}$, standard deviation for heat flow estimate; $\Delta Q$, climatic correction; and $Q_{c}$ climatically corrected heat flow. Symbols indicate units: ${ }^{*} W \cdot m^{-1} \cdot K^{-1} ; \pm: \mu W \cdot m^{-3} ; m^{-1} W m^{-2}$.

succession of deformation events [Bleeker, 1990]. Heat flow variations in the Thompson area are strongly related to thermal conductivity variations, but are not correlated with surface heat production rates (Figure 3). Near the Birchtree Mine, two boreholes, $2 \mathrm{~km}$ apart, yield values of 50 and $64 \mathrm{~mW} \cdot \mathrm{m}^{-2}$. These two boreholes are located on both sides of the transition between gneisses and the Ospwagan metasediments, and hence we consider the two determinations as indepen-

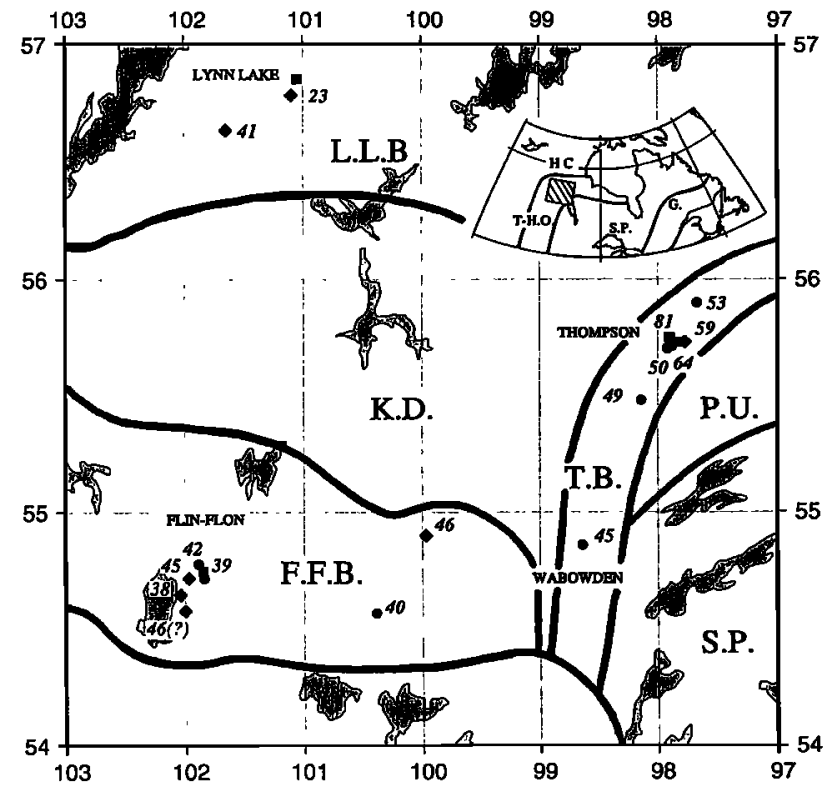

Figure 1. Heat flow values in the eastern TransHudson Orogen (in $m W \cdot m^{-2}$ ). Diamonds correspond to previously published data (Drury, 1985; and references therein). Geological domains are delineated : $L L B$ : Lynn Lake Belt; $K D$ : Kisseynew Domain; $F F B$ : Flin Flon Belt; $T B$ : Thompson Belt; $P U$ : Pikwitonei Uplift; $S P$ : Superior Province. Inset : $H C$ : Hearne Craton; $S P$ : Superior Province; $G$ : Grenville Province. dent. The higher heat flow value is in the more conductive metasediments (Table 1).

Previous studies have calculated heat refraction effects in peculiar geometries [Lee and Henyey, 1974]. For this paper, we have obtained an analytical solution, in

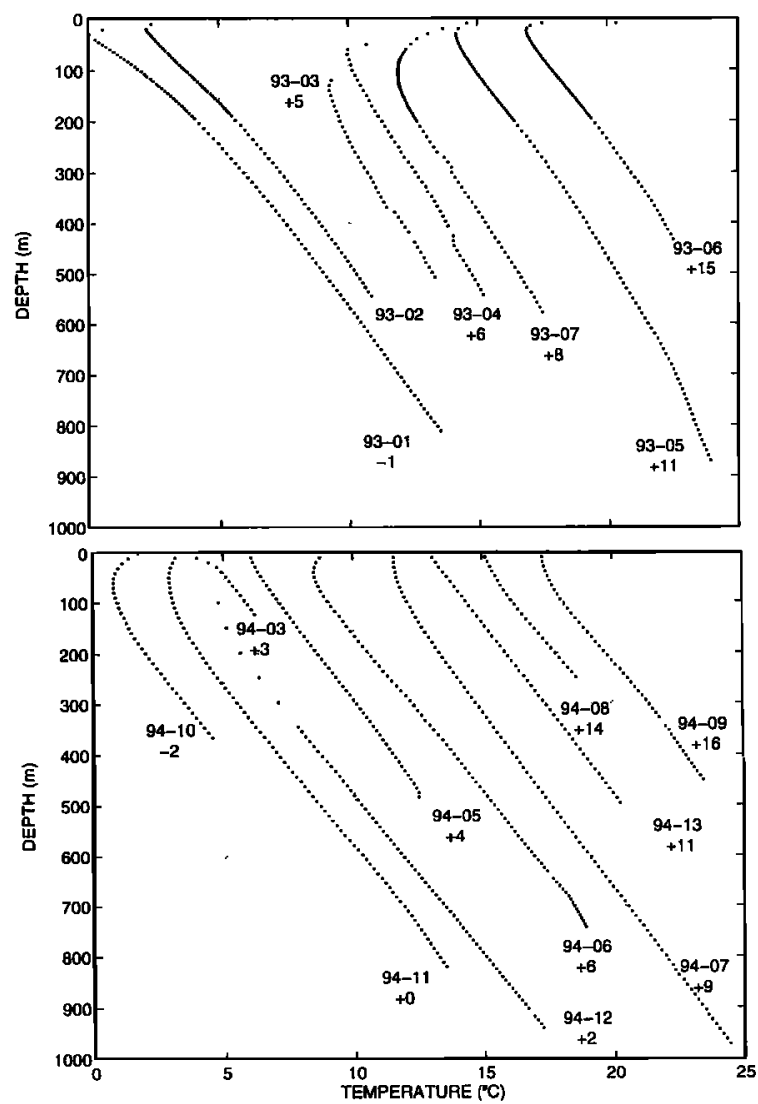

Figure 2. Measured temperature profiles. For clarity, temperature profiles are shifted as indicated. Top: profiles from the Flin Flon Belt and from Wabowden (see Table 1). Bottom: profiles from the Thompson area. 

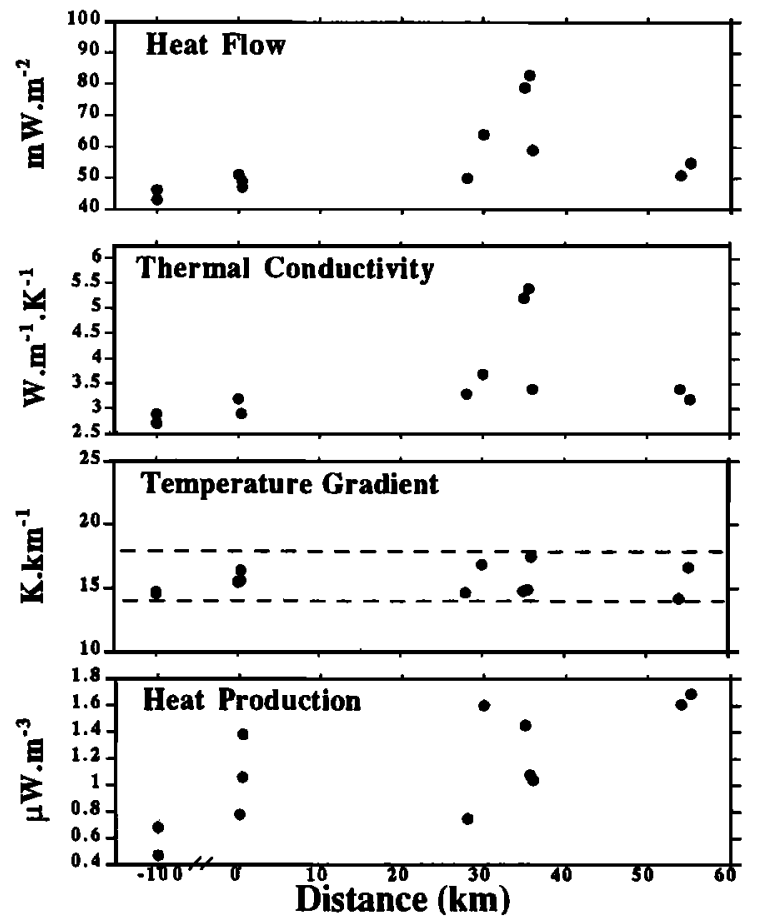

Figure 3. Heat flow, thermal conductivity, temperature gradient and heat production profiles along the Thompson belt. Origin corresponds to borehole 94-11 (see Table 1). Temperature gradients do not vary much and high heat flow values are due to large values of thermal conductivity.

two dimensional and cylindrical geometry, for a conductor embedded in a half-space. The conductor extends from the surface to a depth of 1 ; its half-width (or radius) is $a$. There are no heat sources. Thermal conductivity is $k$ in the conductor and 1 in the surrounding rocks. A constant heat flux of 1 is imposed at depth far from the conductor. The solution, obtained by solving the steady-state heat equation with the boundary conditions, is dimensionless. It represents the ratio of the gradient (or heat flow) affected by refraction to the unperturbed gradient (or heat flow). In cartesian geometry, the solution for surface heat flow is :

$$
\phi_{x<a}(x)=\sum_{n=0}^{\infty} \alpha_{n}+\frac{\alpha_{n}(k-1) \cosh \left(k_{n} x\right)}{k \sinh \left(k_{n} a\right)+\cosh \left(k_{n} a\right)}
$$

and

$\phi_{x>a}(x)=\sum_{n=0}^{\infty} \alpha_{n}+\frac{\alpha_{n}(1-k) \sinh \left(k_{n} a\right) \exp \left(k_{n}(a-x)\right)}{k \sinh \left(k_{n} a\right)+\cosh \left(k_{n} a\right)}$

where

$$
k_{n}=\frac{(2 n+1) \pi}{2}, \quad \alpha_{n}=\frac{4}{\pi} \frac{(-1)^{n}}{(2 n+1)}
$$

In cylindrical geometry, the solution for surface heat flow is obtained with the modified Bessel functions $I_{0}$, $I_{1}, K_{0}, K_{1}$ :

$$
\phi_{r<a}(r)=\sum_{n=0}^{\infty} \alpha_{n}+\frac{\alpha_{n}(k-1) K_{1}\left(k_{n} a\right) I_{0}\left(k_{n} r\right)}{k I_{1}\left(k_{n} a\right) K_{0}\left(k_{n} a\right)+K_{1}\left(k_{n} a\right) I_{0}\left(k_{n} a\right)}
$$

and

$$
\phi_{r>a}(r)=\sum_{n=0}^{\infty} \alpha_{n}+\frac{\alpha_{n}(1-k) I_{1}\left(k_{n} a\right) K_{0}\left(k_{n} r\right)}{k I_{1}\left(k_{n} a\right) K_{0}\left(k_{n} a\right)+K_{1}\left(k_{n} a\right) I_{0}\left(k_{n} a\right)}
$$

Dimensionless heat flow and temperature gradient are shown in Figure 4 for a conductivity contrast of 1.7, which was measured at Thompson. For small $a$, which is relevant here, there is a sharp discontinuity in heat flow at the boundary, with heat flow much enhanced in the conductive body. At the center of the cylindrical anomaly, heat flow is increased by 1.65 . For the same geometry and a conductivity contrast of 2 , the amplification is 1.92 . Outside the conductor, heat flow varies little regardless of the conductivity contrast. Throughout the region, the temperature gradient does not vary much for small $a$.

In the Thompson area, away from the highly conductive metasediments, thermal conductivity values are within the normal range for gneisses and heat flow varies within a restricted range of 45 to $53 \mathrm{~mW} \cdot \mathrm{m}^{-2}$ (Figure 1). Refraction effects are observed at the Birchtree mine and Thompson station sites. The analysis above suggests that the heat flow measured in the low conductivity formation is close to the undisturbed background value. At Birchtree, heat flow is between 50 and 64 $m W \cdot m^{-2}$; the mean value of $57 \mathrm{~mW} \cdot \mathrm{m}^{-2}$ provides an estimate of the undisturbed heat flow with $12 \%$ maximum uncertainty. Near the Thompson station, heat refraction effects are more severe because thermal conductivity contrasts are larger (Figure 3). A heat flow value of $59 \mathrm{~mW} \cdot \mathrm{m}^{-2}$ was obtained by Drury [1987] on gneisses with "normal" thermal conductivity, 3 kilometers away from our boreholes (79 and $83 \mathrm{~mW} \cdot \mathrm{m}^{-2}$ ) located in the "footwall quartzites" of the Pipe formation [Bleeker, 1990]. Consequently, the undisturbed heat
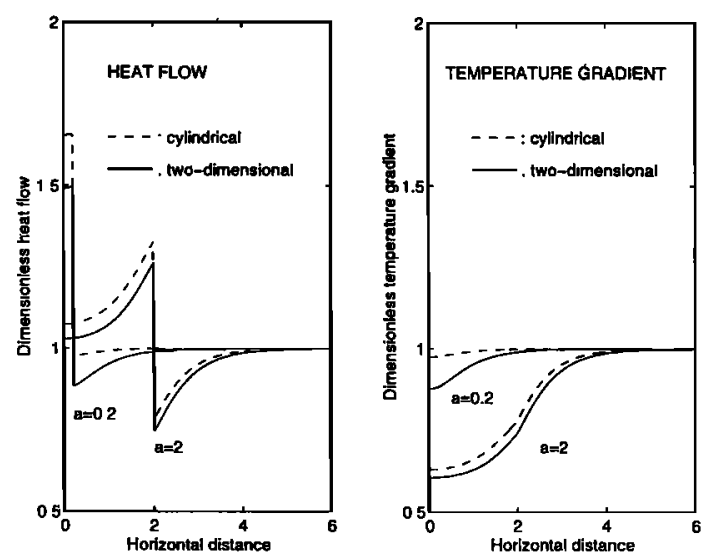

Figure 4. Surface heat flow and temperature gradient variations due to heat refraction by a conductor of thermal conductivity contrast of 1.7 . The dimensionless half-width or radius $a$ is indicated. 


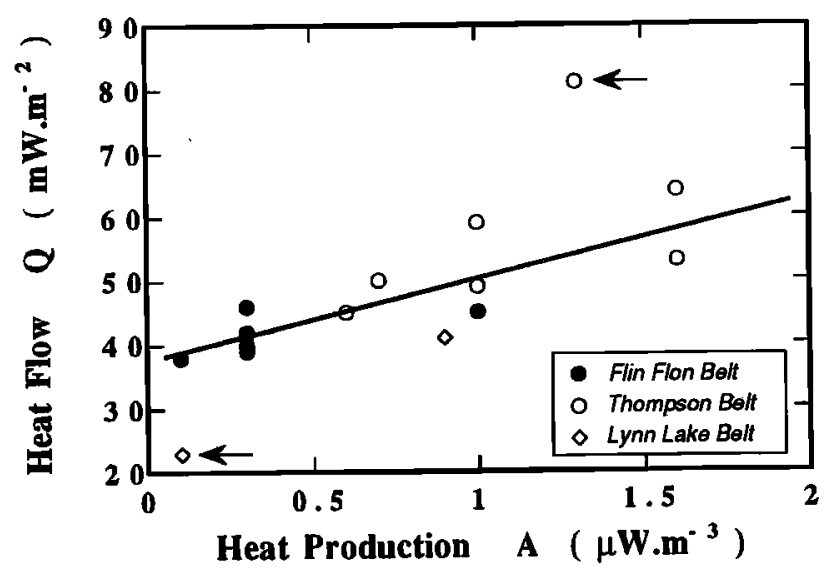

Figure 5. Heat flow and heat production data where Flin Flon, Thompson and Lynn Lake belts are identified. Anomalous data (arrows) were not included in the calculation of the linear relationship " $Q=Q_{r}+A . D$ " (see text).

flow is estimated at $68 \mathrm{~mW} \cdot \mathrm{m}^{-2}$ with $15 \%$ uncertainty (relative to the measured values).

Heat flow values in the TB are higher than in the FFB. Average heat flow is $42 \pm 3($ s.d. $) \mathrm{mW} \cdot \mathrm{m}^{-2}$ in the FFB versus $54 \pm 8(s . d) m. W \cdot m^{-2}$ in the TB. The corresponding average heat production rates are $0.4 \pm$ $0.3(s . d$.$) and 1.2 \pm 0.3(s . d.) \mu W . m^{-3}$. Thus, differences in average crustal composition over a thickness of about $15 \mathrm{~km}$ could account for the difference in heat flow. The relationship between local values of heat flow and heat production is shown in Figure 5. The whole data set (without the two extreme and anomalous values) yields an apparent thickness $D$ for radiogenic heat production of $12.7 \mathrm{~km}$ and reduced heat flow $Q_{r}=38 \mathrm{~mW} \cdot \mathrm{m}^{-2}$.

\section{Discussion}

The Trans-Hudson Orogen represents a collisional structure among several small Archean blocks. Subduction and continental collision are known to induce melting of the lower crust and transport radioactive sources within the crust. This study suggests that, if such events have occurred in the Trans-Hudson Orogen, they were more important near its eastern margin and they led to the concentration of felsic rocks beneath the Thompson belt. Indeed, seismic studies show a variable upper crust overlying a relatively homogeneous lower crust assumed Archean in age [Lucas et al., 1999].

The heat flow data in the THO raise questions about interpretation of the elastic thickness of the lithosphere. In Canada, the elastic lithosphere is thickest $(>120 \mathrm{~km})$ near the THO [Pilkington, 1991]. It is twice as thick as in the eastern Shield. Most of the variability in surface heat flow in the Shield can be accounted for by crustal heat production and the "high" heat flow values in the
THO are not consistent with a lithosphere colder than in the eastern Shield. Concepts dealing with a lithospheric root or a thick elastic lithosphere in the central Canadian Shield could thus be related to differences in composition but not to thermal regime.

Acknowledgments. Helpful comments by W. Bleeker and a constructive review by J. Sass were greatly appreciated. Reviews by P. Armstrong, D. Chapman and P. Stoddard are also acknowledged. This research was supported by NSERC (Canada), FCAR (Québec) and INSU (CNRS, France). This is LITHOPROBE publication 783.

\section{References}

Bleeker, W., New structural-metamorphic constraints on Early Proterozoic oblique collision along the Thompson Nickel Belt, Manitoba, Canada, in Lewry, J.F. and Stauffer,M.R., eds., The Early Proterozoic Trans-Hudson Orogen of North America, Geol. Ass. Canada, Spec. Pap. 37, 57-73, 1990.

Drury, M.J., Heat flow and heat generation in the Churchill Province of the Canadian Shield, and their paleotectonic significance, Tectonophys., 115, 25-44, 1985.

Jessop, A.M., The distribution of glacial perturbation of heat flow in Canada, Can. J. Earth Sci., 8, 162-166, 1971.

Lee, T.C., and T.L. Henyey, Heat-flow refraction along dissimilar media. Geophys. J. Roy. Astr. Soc., 39, 319-333, 1974.

Lewry, J.F., and K.D. Collerson, The Trans-Hudson Orogen : extent, subdivision, and problems, in J.F. Lewry and M.R. Stauffer (Editors), The Early Proterozoic TransHudson Orogen of North-America, Geol. Assoc. Can. Spec. Pap., 37, 1-14, 1990.

Lucas, S.B., A. Green, Z. Hajnal, D. White, J. Lewry, K. Ashton, W. Weber and R. Clowes, Deep seismic profile across a Proterozoic collision zone : surprises at depth, Nature, 363, 339-342, 1993.

Mareschal, J-C., C. Pinet, C. Gariépy, C. Jaupart, G. Bienfait, G. Dalla-Coletta, J. Jolivet and R. Lapointe, New heat flow density and radiogenic heat production data in the Canadian Shield and the Québec Appalachians, Can. J. Earth Sci., 26, 845-852, 1989.

Pilkington M., Mapping elastic lithospheric thickness variations in Canada, Tectonophys., 190, 283-297, 1991.

Pinet, C., C. Jaupart, J-C. Mareschal, C. Gariépy, G. Bienfait and R. Lapointe, Heat flow and structure of the lithosphere in the eastern Canadian Shield, J. Geophys. Res., 96, 19941-19963, 1991.

Sass, J.H., A.H. Lachenbruch and A.M. Jessop, Uniform heat flow in a deep hole in the Canadian Shield and its paleoclimatic implications, J. Geophys. Res., 76, 85868596, 1971 .

L. Guillou-Frottier and J.C. Mareschal, Geotop, UQAM, P.O. 8888, Succ. Centre-Ville, Montreal, H3C 3P8,

Canada, email: laurent or jcm @volcan.geotop.uqam.ca

C. Jaupart, Institut de Physique du Globe de Paris, 4

Place Jussieu, 75252 Paris cedex 05, France, email:

cj@ccr.jussieu.fr

(received April 23, 1996; revised July 10, 1996; accepted August 14, 1996.) 